\title{
RECENT ADVANCES IN IN VITRO FERTILIZATION: PROTEOMICS, SECRETOMICS, METABOLOMICS AND IN VITRO MATURATION
}

\author{
Ercan BASTU, Gulsah KESKIN, Hasan SERDAROGLU
}

Department of Obstetrics and Gynecology, Istanbul University, Faculty of Medicine, Istanbul, Turkey

\section{SUMMARY}

Since its first successful result in 1978, clinicians and researchers have been working on increasing the efficiency and safety of in vitro fertilization (IVF). As a result of advances in technology and understanding of human reproduction, IVF success rates have increased while high-order multiple pregnancy (triplets and more) rates have decreased. On the other, there is opportunity for further improvement as many couples still face 'unexplained infertility' and high rates of twin pregnancies. Latest technologic and scientific improvements in IVF are promising.

The aim of this review is to present the latest advances in the fields of proteomics, secretomics, metabolomics and oocyte culture, how they can potentially improve embryo selection and in vitro maturation (IVM) and subsequently their possible impact on the safety and efficacy of IVF.

Key words: in vitro fertilization, in vitro maturation, metabolomics, proteomics, secretomics

Journal of Turkish Society of Obstetrics and Gynecology, (J Turk Soc Obstet Gynecol), 2013; Vol: 10, Issue: 1, Pages: 1- 8

\section{IN VITRO FERTILIZASYON'DA GÜNCEL YAKLAŞIMLAR: PROTEOMIKLER, SEKRETOMIKLER, METABOLOMIKKLER VE IN VIIRO MATURASYON}

\section{ÖZET}

1978'de insanlarda yapılmış olan ilk başarılı in vitro fertilizasyon (IVF) uygulamasından beri, IVF'nin etkinliğini ve güvenliğini geliştirme çabaları uzmanlar tarafindan sürdürülmektedir. Teknolojideki gelişmeler ve insan üremesi hakkında artan bilgiler ışı̆̆ında, IVF başarı oranları artarken, çoklu gebelik (üçüz, dördüz ve üstü) oranları düşmüştür. Çoğu çift 'açı ılanamayan infertilite' yaşarken, IVF'e bağlı ikiz gebelik oranları halen yüksek olduğu iç in kat edilecek çok mesafe vardır. Ancak son dönemdeki teknolojik ve bilimsel gelişmeler, IVF'te ciddi iyileşme ihtimali vaat etmektedir.

Bu derlemenin amacl, proteomikler, sekretomikler, metabolomikler ve oosit kültürü ile ilgili son gelişmeleri irdelemek, embriyo seçimi ve in vitro maturasyon (IVM) üzerindeki klinik yansımalarına ışık tutmaktır. Ayrıca yakın gelecekte, bu gelişmelerin IVF'in etkinliğini ve güvenliğini nasıl etkileyebileceği de tartışılacaktır.

Anahtar kelimeler: in vitro fertilizasyon, in vitro maturasyon, metabolomikler, proteomikler, sekretomikler

Türk Jinekoloji ve Obstetrik Derneği Dergisi, (J Turk Soc Obstet Gynecol), 2013; Cilt: 10, Sayl: 1, Sayfa: 1-8

Address for Correspondence: Dr. Ercan Baştu. İstanbul Üniversitesi İstanbul Tıp Fakültesi, Kadın Hastalıkları ve Doğum ABD, 34093, İstanbul Phone: +90 (532) 4134195

e-mail: ercan.bastu@istanbul.edu.tr

Received: 03 February 2012, revised: 16 July 2012, accepted: 22 August 2012, online publication: 23 August 2012 


\section{INTRODUCTION}

As the rate of infertility increases all over the world, assisted reproductive technologies (ART) have started to play a more vital role to meet the needs of infertility patients. On the other hand, rate of live birth in women under 35 years old is currently around $40 \%(1)$. Limited knowledge on the development and implantation of the embryo may be the reason for such low rates. However, recent technological and scientific advances have led to significant improvements in in vitro fertilization (IVF) treatment.

There have main two major developments in the field of IVF: (1) to increase the effectiveness and (2) to enhance safety. Briefly, most of the developments in recent years have helped clinicians and researchers to understand the mechanisms on the development of the embryo and pathophysiology of infertility. The development of pre-implantation genetic diagnosis, embryo screening for genetic disorders (which is beyond the scope of this review) and advances in the field of proteomics have deepened our knowledge about the environment and secretions of the embryo and the differences between a normal embryo growth and an abnormal embryo growth. The results of these studies, while providing selection of the 'best' embryo for transfer, can help increase the success rate of IVF. Increased accuracy in the selection of the embryo will result in transferring fewer embryos with a high potential for implantation. This will improve both the maternal and fetal health.

Due to the in vitro maturation treatment of pre-fertilized oocytes, ovarian stimulation may no longer be needed for patients who are at high-risk of hyperstimulation. Widespread usage of this technique will increase success rates in the future in other specific group of patients (i.e. patient with polycystic ovarian syndrome). Lastly, advances in oocyte cryopreservation play an important role in establishing a common practice of fertility.

The aim of this review is to present the latest advances in the fields of proteomics, secretomics, metabolomics and oocyte culture, how they can potentially improve embryo selection and in vitro maturation (IVM) and subsequently their possible impact on the safety and efficacy of IVF.

\section{PROTEOMICS, SECRETOMICS AND METABOLOMICS}

Even if pre-implantation genetic diagnosis tests provide information about the structure of the embryo, the benefit is limited because of the limited knowledge on the development and implantation potential of the embryo. Clinicians still apply a classification method that assesses embryo quality by morphological criteria to decide which embryo should be transferred. However, the morphology cannot predict the implantation rate by itself(2). A reliable, effective and non-invasive method in assessing the development potential of the embryo can increase IVF success rates, while optimizing the single embryo transfer protocol and reducing the incidence of multiple pregnancy.

Researchers have been focusing on proteomics to better understand the function of embryo cells. Proteomics include the analysis of content of the embryo protein and its protein profile. Protein profiles of different embryos can potentially provide information about the outcome of the methods applied such as IVF or cryopreservation. Since proteomic analysis requires cell lysis, it is not possible to utilize it during pretransfer embryo. Therefore, secreted proteins (secretomics) into the IVF culture media have been investigated. Basic premise is that secretory profile of any embryo can be correlated with reproductive success rate. For instance, profiles of successfully implanted embryos can be examined and biomarkers for the optimum embryo transfer may be found. Even genetic profiles of the embryos to be transferred can be examined in a non-invasive ways. As McReynolds et al. have revealed recently lipocalin-1 is a blastocyst's secretome and is in association with aneuploidies ${ }^{(3)}$.

Lately, metabolites of the cell are examined (metabolomics) as well as the proteins in the culture media. Metabolites reflect physiological and metabolic status of the embryo. Some markers can be found to improve reproductive potential by comparing profiles of implanted embryos. Hence, more accurate methods can be established to decide which embryo will be transferred in IVF cycles. In addition, secretomics may also be halepful for aneuploidy embryos. Since aneuploidy embryos have shown various amino acid turnovers compared to genetically normal embryos, in vitro amino acid profiling can give an idea about the health of the embryo's genetic structure(4). 


\section{Analyze techniques in secretomics and proteomics}

In earlier studies a two-dimensional gel electrophoresis (5), Western blot ${ }^{(6)}$ or ELISA test ${ }^{(7)}$ were employed to identify protein in the mouse embryos. However, these techniques required large amount of sample material, or had sensitivity limitations (electrophoresis), or limitation of the number of protein that can be defined at a single time (Western blot, ELISA test).

Recently, mass spectrometry brought a great impetus to embryo proteomics research. Several proteins have been identified by mass spectrometry. The most commonly used technique is surface-assisted laser desorption / ionization technique (SELDI) together with 'time-of-flight' (TOF). It helps to ionize bound proteins by laser. The resulting gas ions passing through a vacuum TOF tube reach the detector plate. Because ions have different dimensions, reaching speeds to the plate are also different. Hence, the ions are separated according to the mass-charge ratios and profiles are then examined. By this method Katz-Jaffe et al, compared the protein profiles in developing and degenerating embryos ${ }^{(8)}$. These authors have demonstrated the inadequacy of morphological evaluation for embryo selection revealing differences of similar protein in morphology embryos. Since some proteins are released in the media that surrounds the embryo, researchers examined the protein in embryo culture media to create an embryo secretome profile. Katz-Jaffe et al. who conducted a research with surfaceassisted laser desorption / ionization technique together with TOF analysis described different secrotomic profiles in different stages in the development of the embryo and identified that blastocyst development is associated with ubiquitin which is a protein biomarker (9). Ubiquitin is a part of ubiquitin-dependent proteasome system that leads protein to degradation. This system plays a role in proliferation and apoptosis. Reportedly, it increases body fluids in various disease states ${ }^{(10)}$. In addition, it plays a critical role in activities and destruction of key signal molecules during the implantation process ${ }^{(11)}$.

Protein microarray technology has recently been used to compare secretomic profiles in culture medium of implanted blastocysts. Results have showed increased levels of granulocyte-macrophage colony-stimulating factor (GM-CSF) and chemokine (C-X-C motif) ligand 13 (CXCL13) in successfully implanted embryos ${ }^{(12)}$. In this matter, unknown proteins are firstly analyzed and later described by mass spectrometer. In microarray technology protein-specific antibodies have to be used. Therefore, the microarray technology may be more useful to reveal individual markers than identifying protein profile.

\section{Evaluation techniques of metabolomics}

Waste culture media as a result of IVF can be examined by different methods. It is possible for metabolites to be examined. Consequently, information is available about the metabolic status of the embryo. Several spectroscopic techniques used to identify and compare the samples.

Near-infrared spectroscopy and Raman spectroscopic techniques are both vibrational spectroscopic techniques. They produce a metabolite profile according to vibrational characteristics of molecules in the sample. Both techniques have advantages and disadvantages in terms of density of the signal produced and defining specific sample components. Seli et al. have identified differences in metabolite profiles of implanted and non- implanted embryos using both techniques ${ }^{(13)}$. Then, the information obtained was used to create a viability index that was useful in measuring reproductive potential of other embryos. Although retrospective, both techniques evaluated the viability of embryos successfully.

Magnetic resonance spectroscopy is used for identification of metabolites by molecular behavior in the magnetic field. Consequently, differences of the embryos' metabolite profiles were described. In a study with magnetic resonance spectroscopy by Seli et al., implanting embryos revealed a higher glutamate concentrations in culture media than non-implanted embryos $^{(14)}$. In addition, although not statistically significant, the implanting embryo media had lesser extent alanine, pyruvate and glucose. Researchers formed viability index that can predict the success of reproduction in light of these results (sensitivity of $88.2 \%)$.

Although magnetic resonance spectroscopy and Raman spectroscopy results have been similar so far, magnetic resonance spectroscopy is a more expensive and timeconsuming method in terms of data collection and analysis in clinical practice ${ }^{(15)}$. In clinical practice, an ideal analytical technique for metabolomic profiling of embryo culture media has not been found as of yet. The combination of more than one test may be necessary 
for successful prediction. In addition, in current practice, frozen culture media samples have been transported to another laboratory for analysis. When metabolomics profiling can be performed in the IVF centers, we will be able to see exactly how sensitive and successful results really are. In addition, different types of culture media are used in IVF centers, and transfers are done in different stages of pre-implantation. Metabolic profiling appears to have the ability to give independent results after normalization of these factors. On the other hand, how these factors affect the sensitivity of the profiling is still not clearly recognized. Finally, as aneuploidy plays a major role in the loss of embryos in IVF treatment, metabolomics profiling success will depend on its ability to determine aneuploidy embryos.

\section{Clinical Practice}

Secretomic analysis of culture media, which is not invasive for the embryo, has started to find its place in clinical practice. In 2002, Fuzzi et al. found a correlation between successful embryo implantation and soluble human leukocyte antigen G (HLA-G) in IVF culture media ${ }^{(16)}$. As a result, Sher et al. selected embryos according to the state of HLA-G(17). HLAG-positive embryos' implantation and pregnancy rates were significantly higher in comparison to the HLA$\mathrm{G}$ negative embryos. Therefore, HLA-G can be a predictive marker for selection of embryos.

Metabolomics have not been still utilized prospectively in the selection of embryos for transferring. Recent research gives hope for potential clinical applications. Scott et al. were able to estimate the reproductive potential of day- 3 and day- 5 embryos prospectively with Raman spectroscopy on the basis of calculated viability index ${ }^{(18)}$. Successful pregnancy outcome or unsuccessful implantation was estimated with $80.5 \%$ diagnostic sensitivity. With this technique, culture media metabolites are evaluated rapidly. Therefore, it has potential use for selection of embryos before transferring.

In single embryo transfer, as well as the traditional morphological classification, metabolomics evaluation of embryo quality has been the subject of two recent studies ${ }^{(19,20)}$. These authors could not find a correlation between metabolomics viability index and morphological classifications of day-2 or day-3 embryos. Although their studies were retrospective, Seli et al. proved that they were able to predict embryo's reproductive potential while being blinded to pregnancy outcome $^{(20)}$. All these data suggest there are potential benefits to metabolomics evaluation for embryo selection process. As the researchers pointed out, this method is more applicable to estimate higher reproductive potential between two embryos with the same morphological range particularly in single embryo transfer.

\section{IN VITRO MATURATION (IVM)}

Collection of oocytes, fertilization and the transferring of embryos into the uterine cavity are the basic stages of IVF process. In the conventional method, exogenous gonadotropins are administered to the patients and a large number of oocyte development is stimulated. Then oocytes are aspirated via transvaginal route. Antral follicles, which occur due to follicle-stimulating hormone (FSH), reach into Graafian stage before the oocyte pickup process. The greatest benefit of this method is that it mimics the development of normal follicles in vivo (although in supraphysiologic mileu). On the other hand, the process of controlled ovarian stimulation has many disadvantages as well. The high cost of drugs and the risk of ovarian hyperstimulation syndrome (accounted for $10 \%$ of the risky patients) $)^{(21)}$ are just a few examples of the disadvantages.

Since utilizing unstimulated antral follicles, there is no need for gonadotropin therapy in IVM, which is an alternative method. Antral follicles containing oocytes are arrested in prophase stage of meiosis I and cultured in vitro till metaphase stage of meiosis II for 24-48 hours. At the end of this period, maturing oocytes are fertilized either via standard insemination or intracytoplasmic sperm injection method(22,23).

The first baby that was born live by IVM was reported by Cha et al. in $1991^{(24)}$. As we understand the process of folliculogenesis better in the recent years, several progresses have been made in IVM techniques, like culture media and oocyte collection (with prior preparation with FSH or hCG). Today, researchers work on follicular growth in ovarian tissue IVM and subsequent development before IVF. On the other hand, most of the literature on IVM is so far consists of case reports or contains a small number of patients. Therefore, the data obtained is still inadequate. In the future, after more comprehensive studies on IVM, it 
may offer more patient-friendly alternative than ovarian stimulation to infertile patients as well as the option of fertility preservation.

\section{Culture Media}

Oocytes' culture media plays a major role in their development during IVM. Different compositions of culture media for maturation of oocytes have been compared evaluated ${ }^{(25)}$, but there is still no consensus on the optimum composition of the culture media. On the other hand, it is evident that the selected media effects both oocyte maturation rate and the energy consumption(26).

Studies showed that the energy source of oocyte is pyruvate during $\operatorname{IVM}^{(26)}$. Because of the role of gonadotropins in IVM, recombinant FSH, luteinizing hormone (LH), or hCG is added IVM to culture media.

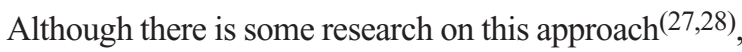
advanced studies on the role of gonadotropins are still needed to better understand the process of oocytes IVM. Serum in the culture media is a source of albumin and steroid precursor as well as growth factors for cells. If there is no serum in the media, additional albumin support is important(22).

Since oocytes epigenetic modifications occur during the process of maturation, culture conditions and their potential effects of IVM are important $(22,29)$. More studies are needed to reveal the net effect of IVM on epigenetic modification. In the future, oocytes' epigenetic profiling may be necessary prior to fertilization and transfer.

\section{Oocyte pick-up}

Oocyte collection technique in IVM is very similar to IVF. However, the pre-treatment improvements have increased the success rate of collection. As a result of many studies, hCG administration in vivo has increased the rate of oocyte in vitro maturation before oocyte pickup ${ }^{(30-32)}$. This approach has been utilized in patients with out without polycystic ovaries $(33,34)$.

Prior to oocyte maturation in vivo, impact of FSH treatment on pregnancy rates reveals inconsistent findings. Many researchers have shown increased number of oocytes collected and the maturation potential of these oocytes with FSH treatment in patients without $\operatorname{PCOS}\left({ }^{(3)}\right.$, and in patients with $\operatorname{PCOS}\left({ }^{36)}\right.$. However, other studies of FSH treatment revealed no increase in maturation, fertilization or pregnancy rates in these two groups $(37,38)$. Fadini et al. recently prospectively administered different gonadotropins, prior to the oocyte pick-up process ${ }^{(32)}$. In this study, no gonadotropin was administered to the control group. One group received only FSH, and the other received only hCG. Another group received both of FSH and hCG. Oocyte maturation rates were higher in only hCG and hCG plus FSH groups. Clinically, the most valuable finding was the highest clinical pregnancy rate in the group given FSH and hCG (29.9\%). Results of this study proved that gonadotropins can be useful for the multiple usages.

The timing of oocyte pick-up is also very important for the success of IVM. Son et al. compared the results of measurement of dominant follicle at the time of collection and IVM results in PCOS patients ${ }^{(39)}$. They showed that large follicles ( $>14 \mathrm{~mm}$ ) had higher implantation and clinical pregnancy rates than small follicles $(<14 \mathrm{~mm})$. These results have to be confirmed by additional prospective studies, yet it appears to be an important approach to improve IVM protocols.

\section{Clinical practice}

As in vitro oocyte maturation does not require extensive gonadotropin stimulation, it provides a great advantage to patients who are at risk of ovarian hyperstimulation syndrome. For this reason, many studies on clinical application of IVM have been carried out in PCOs patients who were at high risk of ovarian hyperstimulation syndrome. The results of such studies were as follows: fertilization rate of $73.3 \%(34)$, implantation rate of $21.6 \%{ }^{(36)}$, clinical pregnancy rate of $40.3 \%(39)$ and live birth rate of $15.9 \%(40)$ IVM was successfully implemented in patients with poor responsive ovarian stimulation(39). If the growth of oocytes was not sufficient, or the number of oocytes that responded to exogenous gonadotropins was not enough, the cycle was canceled. However, Liu et al. aspirated such immature oocytes $(\leq 14 \mathrm{~mm})$ and demonstrated their maturation in vitro ${ }^{(41)}$. As a result of this study: fertilization rate of $78.8 \%$, implantation rate of $20 \%$ and a total of 8 cycles, 2 live births (1 ongoing pregnancy) have emerged. Therefore, IVM can be an interesting option for poor responders as well as hyper-responders.

\section{In Vitro Follicular Maturation}

Those at risk of hyperstimulation or show poor response 
to gonadotropins present a number of exciting options for IVM, whose oocytes in the stage of antral follicles are required. On the other hand, primordial or pre-antral stage follicles have to be collected in vitro maturation. The main objective of this technique is to ensure the development of follicles up to the antral stage. For fertility preservation in patients undergoing chemotherapy or radiation therapy, achieving success in IVM can a groundbreaking development. Although a successful pregnancy has not reported yet, researchers continue to work on both humans and animals.

Cortical tissue biopsy in humans is usually performed during gynecologic surgery or cesarean section(42-44). Before culturing, follicles are isolated either mechanically ${ }^{(45)}$ or by melting enzymatic stroma around (42). Despite a sufficient number of follicles isolated, follicles undergo atresia after a few days in culture because of being away from ovarian stroma support. Hence, researchers began to culture ovarian cortical strips carrying primordial follicles $(43,44)$. In a study using this method, over $66 \%$ of cortex follicles remained intact for four weeks in culture and most of them reached the primary and secondary stages of development ${ }^{(44)}$. More research is still needed to evaluate whether oocytes obtained by this method provide adequate maturation and fertilize successfully.

Telfer et al. matured in vitro primordial / primary follicles up to the antral stage by the two-digit cultural system ${ }^{(43)}$. Ovarian cortical tissue biopsies in serum-free media cultured for six days and pre-antral follicles were isolated for cultuvation again with activin A. Though antral formation was reached only in $30 \%$ of the oocytes, this technique can provide an alternative for the development of follicles in vitro before IVM.

Somatic cells (granulosa and theca cells surrounding the oocyte inside the follicle, etc.) need glucose, regardless of the technique used for the development in-vitro prior to IVM, while oocytes use pyruvate as an energy source. Hence, the ingredients added to the media should be carefully selected and set to create a right development environment.

\section{Conclusion}

Despite of the differences in the above-mentioned developments, the common goal is the same to increase the success rate while improving patient safety. As multiple pregnancy is an important concern of ART, single-embryo transfer is the only solution to reduce the incidence of twin or multiple pregnancy. As long as single embryo transfer does not provide comparable results to multiple embryo transfers, its usage will be limited to mandatory laws like in Turkey. If our ability to choose genetically healthy embryos with the highest reproductive potential with help of metabolomics and secretomics increases, single embryo transfer may be optimized. IVM technique reduces the risk of ovarian hyperstimulation syndrome and increases patient safety. In addition, IVM may be an interesting alternative for patients who are poor responders or patients who require fertility preservation. Although extensive research is needed before routine clinical practice, the above-mentioned recent developments are quite promising in improving ART outcomes.

\section{REFERENCES}

1. Society for Assisted Reproductive Technology IVF database. http://www.sart.org

2. Borini A, Lagalla C, Cattoli M, Sereni E, Sciajno R, Flamigni $\mathrm{C}$ and Coticchio G. Predictive factors for embryo implantation potential. Reprod Biomed Online 2005; 10: 653- 68.

3. McReynolds S, Vanderlinden L, Stevensens J, Hansen K, Schoolcraft W, Katz- Jaffe M. Lipocalin-1: a potential marker for noninvasive aneuploidy screening. Fertil. Steril 2011: 95: $2631-3$

4. Picton H, Elder K, Hougton F. Association between amino acid turnover and chromosome aneuploidy during human preimplantation embryo development in vitro. Molecular Human Rep. 2010: 557- 69.

5. Latham KE, Garrels JI, Chang C, and Solter D. Analysis of embryonic mouse development: construction of a highresolution, two-dimensional gel protein database. Appl Theor Electrophor 1992; 2: 163- 170.

6. Navarrete Santos A, Tonack S, Kirstein M, Kietz S and Fischer B. Two insulin-responsive glucose transporter isoforms and the insulin receptor are developmentally expressed in rabbit preimplantation embryos. Reproduction 2004; 128: 503- 16.

7. Noci I, Fuzzi B, Rizzo R, Melchiorri L, Criscuoli L, Dabizzi S, Biagiotti R, Pellegrini S, Menicucci A and Baricordi OR. Embryonic soluble HLA-G as a marker of developmental potential in embryos. Hum Reprod 2005; 20: 138- 46.

8. Katz-Jaffe MG, Gardner DK and Schoolcraft WB. Proteomic analysis of individual human embryos to identify novel biomarkers of development and viability. Fertil Steril 2006; 85: $101-7$. 
9. Katz-Jaffe MG, Schoolcraft WB and Gardner DK. Analysis of protein expression (secretome) by human and mouse preimplantation embryos. Fertil Steril 2006; 86: 678- 85 .

10. Sandoval JA, Hoelz DJ, Woodruff HA, Powell RL, Jay CL, Grosfeld JL, Hickey RJ, Malkas LH. Novel peptides secreted from human neuroblastoma: useful clinical tools? J Pediatr Surg 2006 ;41: 245- 51.

11. Wang Y, Puscheck EE, Lewis JJ, Trostinskaia AB, Wang F, Rappolee DA. Increases in phosphorilation of SAPK/JNK and P38MAPK correlate negatively with mouse embryo development after culture in different media. Fertil Steril 2005; 1: 1144- 54

12. Dominguez F, Gadea B, Esteban FJ, Horcajadas JA, Pellicer A and Simón C. Comparative protein-profile analysis of implanted versus non-implanted human blastocysts. Hum Reprod 2008; 23: 1993- 2000.

13. Seli E, Sakkas D, Scott R, Kwok SC, Rosendahl SM and Burns DH. Noninvasive metabolomic profiling of embryo culture media using Raman and near-infrared spectroscopy correlates with reproductive potential of embryos in women undergoing in vitro fertilization. Fertil Steril 2007; 88: 1350-7.

14. Seli E, Botros L, Sakkas D and Burns DH. Noninvasive metabolomic profiling of embryo culture media using proton nuclear magnetic resonance correlates with reproductive potential of embryos in women undergoing in vitro fertilization. Fertil Steril 2008; 90: 2183- 9.

15. Botros L, Sakkas D and Seli E. Metabolomics and its application for non-invasive embryo assessment in IVF. Mol Hum Reprod 2009; 14: 679- 90.

16. Fuzzi B, Rizzo R, Criscuoli L, Noci I, Melchiorri L, Scarselli B, Bencini E, Menicucci A and Baricordi OR. HLA-G expression in early embryos is a fundamental prerequisite for the obtainment of pregnancy. Eur J Immunol 2002; 32, 311 315.

17. Sher G, Keskintepe L, Fisch JD, Acacio BA, Ahlering P, Batzofin J and Ginsburg M. Soluble human leukocyte antigen $\mathrm{G}$ expression in phase I culture media at 46 hours after fertilization predicts pregnancy and implantation from day 3 embryo transfer. Fertil Steril 2005; 83: 1410- 3.

18. Scott R, Seli E, Miller K, Sakkas D, Scott K and Burns DH. Noninvasive metabolomic profiling of human embryo culture media using Raman spectroscopy predicts embryonic reproductive potential: a prospective blinded pilot study. Fertil Steril 2008; 90: 77- 83 .

19. Vergouw CG, Botros LL, Roos P, Lens JW, Schats R, Hompes PG, Burns DH and Lambalk CB. Metabolomic profiling by near-infrared spectroscopy as a tool to assess embryo viability: a novel, non-invasive method for embryo selection. Hum
Reprod 2008; 23: 1499- 1504

20. Seli E, Vergouw CG, Morita H, Botros L, Roos P, Lambalk CB, Yamashita N, Kato O and Sakkas D. Noninvasive metabolomic profiling as an adjunct to morphology for noninvasive embryo assessment in women undergoing single embryo transfer. Fertil Steril 2010; 94(2): 535- 42.

21. MacDougall MJ, Tan SL, Balen A and Jacobs HS. A controlled study comparing patients with and without polycystic ovaries undergoing in-vitro fertilization. Hum Reprod 1993; 8: 233237.

22. Picton HM, Harris SE, Muruvi W and Chambers EL. The in vitro growth and maturation of follicles. Reproduction 2008; 136: $703-15$.

23. Loutradis D, Kiapekou E, Zapanti E and Antsaklis A. Oocyte maturation in assisted reproductive techniques. Ann NY Acad Sci 2006; 1092: 235- 46

24. Cha KY, Koo JJ, Ko JJ, Choi DH, Han SY and Yoon TK. Pregnancy after in vitro fertilization of human follicular oocytes collected from nonstimulated cycles, their culture in vitro, and their transfer in a donor oocyte program. Fertil Steril 1991; 55: 109- 13.

25. Filali M, Hesters L, Tachdjian G, Tachdjian G, Frydman R and Frydman N. Retrospective comparison of two media for in-vitro maturation of oocytes. Reprod Biomed Online 2008; 16: 250- 6 .

26. Roberts R, Franks S and Hardy K. Culture environment modulates maturation and metabolism of human oocytes. Hum Reprod 2002; 17: 2950- 6.

27. Anderiesz C, Ferraretti A, Magli C, Fiorentino A, Fortini D, Gianaroli L, Jones GM and Trounson AO. Effect of recombinant human gonadotrophins on human, bovine and murine oocyte meiosis, fertilization and embryonic development in vitro. Hum Reprod 2000; 15: 1140- 8.

28. Ge HS, Huang XF, Zhang W, Zhao JZ, Lin JJ and Zhou W. Exposure to human chorionic gonadotropin during in vitro maturation does not improve the maturation rate and developmental potential of immature oocytes from patients with polycystic ovary syndrome. Fertil Steril 2008; 89: 98103.

29. Huntriss $\mathbf{J}$ and Picton H. Epigenetic consequences of assisted reproduction and infertility on the human preimplantation embryo. Hum Fertil 2008; 11: 85- 94.

30. Chian RC, Gulekli B, Buckett WM and Tan SL. Priming with human chorionic gonadotropin before retrieval of immature oocytes in women with infertility due to the polycystic ovary syndrome. N Engl J Med 1999; 341: 1624- 6.

31. Chian RC, Buckett WM, Tulandi T and Tan SL. Prospective randomized study of human chorionic gonadotrophin priming 
before immature oocyte retrieval from unstimulated women with polycystic ovarian syndrome. Hum Reprod 2000; 15 : 165- 170 .

32. Fadini R, Dal Canto MB, Mignini Renzini M, Brambillasca F, Comi R, Fumagalli D, Lain M, Merola M, Milani R and De Ponti E. Effect of different gonadotrophin priming on IVM of oocytes from women with normal ovaries: a prospective randomized study. Reprod Biomed Online 2009; 19: $343-51$

33. Holzer H, Scharf E, Chian RC, Demirtas E, Buckett W and Tan SL. In vitro maturation of oocytes collected from unstimulated ovaries for oocyte donation. Fertil Steril 2007; 88: $62-7$.

34. Le Du A, Kadoch IJ, Bourcigaux N, Doumerc S, Bourrier MC, Chevalier N, Fanchin R, Chian RC, Tachdjian G, Frydman $\mathrm{R}$ and Frydman N. In vitro oocyte maturation for the treatment of infertility associated with polycystic ovarian syndrome: the French experience. Hum Reprod 2005; 20: 420- 4.

35. Wynn P, Picton HM, Krapez JA, Rutherford AJ, Balen AH and Gosden RG. Pretreatment with follicle stimulating hormone promotes the numbers of human oocytes reaching metaphase II by in-vitro maturation. Hum Reprod 1998; 13: 3132- 8.

36. Mikkelsen AL and Lindenberg S. Benefit of FSH priming of women with PCOS to the in vitro maturation procedure and the outcome: a randomized prospective study. Reproduction 2001; 122: 587- 92 .

37. Mikkelsen AL, Smith SD and Lindenberg S. In-vitro maturation of human oocytes from regularly menstruating women may be successful without follicle stimulating hormone priming. Hum Reprod 1999; 14: 1847- 51.

38. Lin YH, Hwang JL, Huang LW, Mu SC, Seow KM, Chung
J, Hsieh BC, Huang SC, Chen CY and Chen PH. Combination of FSH priming and hCG priming for in-vitro maturation of human oocytes. Hum Reprod 2003; 18: 1632- 6.

39. Son WY, Chung JT, Herrero B, Dean N, Demirtas E, Holzer H, Elizur S, Chian RC and Tan SL. Selection of the optimal day for oocyte retrieval based on the diameter of the dominant follicle in hCG-primed in vitro maturation cycles. Hum Reprod 2008; 23: 2680- 5 .

40. Child TJ, Phillips SJ, Abdul-Jalil AK, Gulekli B and Tan SL. A comparison of in vitro maturation and in vitro fertilization for women with polycystic ovaries. Obstet Gynecol 2002; 100: $665-70$.

41. Liu J, Lu G, Qian Y, Mao Y and Ding W. Pregnancies and births achieved from in vitro matured oocytes retrieved from poor responders undergoing stimulation in in vitro fertilization cycles. Fertil Steril 2003; 80: 447- 9.

42. Rice S, Ojha $\mathrm{K}$ and Mason H. Human ovarian biopsies as a viable source of pre-antral follicles. Hum Reprod 2008; 23: 600- 5 .

43. Telfer EE, McLaughlin M, Ding C and Thong KJ. A two-step serum-free culture system supports development of human oocytes from primordial follicles in the presence of activin. Hum Reprod 2008; 23: 1151- 8.

44. Hovatta O, Wright C, Krausz T, Hardy K and Winston RM. Human primordial, primary and secondary ovarian follicles in long-term culture: effect of partial isolation. Hum Reprod 1999; 14: 2519- 24.

45. Abir R, Franks S, Mobberley MA, Moore PA, Margara RA and Winston RM. Mechanical isolation and in vitro growth of preantral and small antral human follicles. Fertil Steril 1997; 68: 682-8. 